\title{
Diretores de escolas públicas: aspectos do trabalho docente
}

\section{Public Schools Principals: aspects of teaching work}

\author{
Ângelo Ricardo de Souza ${ }^{1}$ \\ Andréa Barbosa Gouveia ${ }^{2}$
}

\begin{abstract}
RESUMO
O artigo, inicialmente, apresenta uma discussão sobre alguns aspectos do trabalho docente concernente à função de diretor escolar na educação pública brasileira. Considera, para tanto, elementos conceituais como a definição da função dirigente escolar e as respectivas noções de carreira e remuneração, cotejadas às diferentes faces desse tipo de trabalho. $\mathrm{Na}$ segunda parte, o texto mostra uma análise sobre os diretores escolares no Brasil e no Paraná, sendo que para aqueles toma dados da base nacional do Sistema de Avaliação da Educação Básica - SAEB de 2007 -, e para estes utiliza uma base de dados própria dos autores, construída com respostas a questionário aplicado aos diretores que participaram do programa de formação Escola de Gestores, na modalidade EAD, entre 2008 e 2009, na Universidade Federal do Paraná.

Palavras-chave: diretor escolar; escola de gestores; trabalho docente.
\end{abstract}

\begin{abstract}
This article, initially, presents a discussion about some aspects of teachers work concerning the role of school principals in the Brazilian public education. Thus, it considers conceptual elements as the definition of a school principal role and consequent notions of career and salary, analyzing the different faces of this kind of work. In the second part, the text introduces an analysis of the school principals in Brazil and Parana, and for those it takes data from the National Evaluation System of Basic Education -

1 Doutor em Educação. Professor do Núcleo de Políticas Educacionais e do Programa de Pós-Graduação em Educação da Universidade Federal do Paraná, Brasil. E-mail: angelo@ufpr.br

2 Doutora em Educação. Professora do Núcleo de Políticas Educacionais e do Programa de Pós-Graduação em Educação da Universidade Federal do Paraná, Brasil. E-mail: andreabg@ufpr.br
\end{abstract}


SAEB 2007 -, and for these it uses a database constructed by the authors with answers to a questionnaire responded by principals who participated in the training program called "Escola de Gestores" (ODL mode) between 2008 and 2009 at the Federal University of Parana.

Keywords: school principal; "escola de gestores"; teachers work.

O princípio constitucional da gestão democrática na escola pública, combinado com as determinações da Lei de Diretrizes e Bases da Educação, Lei $\mathrm{n}^{\mathrm{o}}$ 9.394/96, sobre a necessidade de que os sistemas de ensino devem dotar as escolas de autonomia pedagógica, administrativa e de gestão financeira, tem resultado em múltiplos cenários de discussão sobre o papel do dirigente escolar. Assim, seja numa perspectiva de construção coletiva da democracia na escola, seja na perspectiva da responsabilização dos agentes escolares pelos resultados educacionais, explicita-se a preocupação com a formação e com as condições de trabalho dos dirigentes escolares.

Nesse cenário, a proposta de qualificação em serviço que o Ministério da Educação construiu para a formação de diretores escolares denominada "Escola de Gestores" traz elementos novos e interessantes, à medida que a União financia e coloca à disposição dos sistemas públicos de ensino uma ferramenta de formação que pode vir a construir mais unidade na compreensão dos processos escolares. Todavia, ainda são necessárias mais avaliações que tomem os resultados e os impactos desse programa para uma análise mais qualificada acerca da efetividade do investimento realizado nesse tipo de formação.

Com o espírito de contribuir para tal avaliação, é importante conhecer os sujeitos que participam desse processo, seu perfil e sua percepção sobre o programa. Este artigo produz um levantamento desses aspectos a partir de dados coletados junto aos diretores de escolas públicas que participaram do Curso de Especialização em Gestão Escolar (Programa Escola de Gestores) no Estado do Paraná, mas para se ter uma dimensão comparativa com o universo dos diretores das escolas públicas brasileiras, o trabalho também coteja aquele levantamento com o perfil dos diretores em atuação no Brasil, identificado a partir dos dados nacionais do Sistema de Avaliação da Educação Brasileira, de sorte a avaliar em que medida tal proposta de formação tem aderência e/ou relação com as necessidades da escola básica e com o trabalho docente.

Nesse estudo, a direção escolar é compreendida como a função ${ }^{3}$ de coordenação político-pedagógica e institucional (administrativa e representativa) da

3 Entendemos que a direção escolar, na esfera pública, não é um cargo e sim uma função a ser desempenhada pelo ocupante de cargo docente (professor, pedagogo, educador...). Essa questão é evidentemente complexa e está no centro das discussões sobre a (in)constitucionalidade da legislação que determina que o processo de escolha de diretores nas escolas públicas se dê por meio de eleições diretas na comunidade escolar. 
escola. Normalmente, é desempenhada por um profissional da educação (eleito, indicado, concursado), que representa o poder instituído na escola e tem por tarefa primordial coordenar a gestão escolar, representar a instituição, responder administrativa e politicamente, zelar, dar suporte e fazer cumprir os objetivos pedagógicos da escola.

O artigo está organizado de maneira que, inicialmente, procuramos apresentar algumas ideias sobre a condição docente do dirigente escolar, destacadamente sobre a formação e a remuneração. E, na parte final do artigo, expomos e discutimos dados coletados pelo Sistema de Avaliação da Educação Básica - SAEB, de 2007 - sobre os diretores escolares, cotejadamente a dados coletados por um questionário aplicado pelos autores junto aos diretores que participaram do Programa Escola de Gestores no Estado do Paraná, entre 2008 e 2010.

\section{Direção escolar e aspectos da formação e da remuneração docente}

A natureza do trabalho do dirigente escolar é, essencialmente, política. Todavia, ela é de política educacional/escolar. Os diretores têm a tarefa de conduzir o processo político que é a gestão da escola, porém são cobrados com base em padrões muito distintos acerca dessa natureza (político-pedagógica) e tais padrões de referência sobre como se comportar na condução de uma escola não são emersos da função social da escola. Ao contrário, o que parece ocorrer é uma cobrança sobre o dirigente escolar tomando por base uma face técnico-administrativa da sua função, mais adiante comentada. E os mundos da administração, das finanças, das empresas e corporações, assim como da política, são mundos masculinos e masculinizados, seja no Brasil ou no exterior (ECKMAN, 2004; COLLARD, 2001; SOUZA, 2007). A presença quantitativamente dominante de mulheres na função decorre da predominância feminina na profissão docente, mas estudos têm mostrado que há algum grau de discriminação entre homens e mulheres no acesso à direção escolar e nas suas condições de trabalho (SOUZA, 2007; CORREA, 2010), em especial no que se refere às condições salariais cotejadamente ao nível de formação e ao tempo de serviço. Como tal desigualdade não parece existir entre os docentes (GATTI; BARRETO, 2009), é possível que ela tenha relação com a função de dirigente escolar articuladamente à questão do poder, isto é, onde a presença do poder é mais forte (de acesso, de disputa, de operação etc.), parece haver elementos de maior desigualdade e discriminação. Contudo, os dados apresentados mais adiante sugerem que tal desigualdade pode estar em retração. 
Outro aspecto importante na identificação do dirigente escolar como trabalhador docente diz respeito às formações inicial e continuada, sendo que ambas são aspectos de muita discussão no que tange à função de diretor escolar. Àquela recai o debate acerca da necessidade (ou não) de uma formação específica em administração escolar para o desenvolvimento do trabalho.

Mas, pesquisas têm mostrado que, aparentemente, não há significativa diferenciação nos resultados do trabalho docente desenvolvido pelo diretor escolar com habilitação específica em administração escolar em relação àqueles com outra formação docente, pois parece que "os gestores na educação agem, comumentemente, baseados em seu bom senso, ou ainda, a partir de um senso prático acerca do que é correto para ser efetivado, o qual emerge da experiência e não da teoria" (LITTRELL; FOSTER, 1995, p. 32). Assim,

as avaliações indicam que os professores não especializados em gestão educacional nem em nível de formação inicial nem com formação continuada, isto é, educadores que assumiram a função dirigente sem a base de conhecimentos tida como própria do campo e que também não tiveram acesso a ela durante o tempo em que estavam na direção, não se saíam nem melhor nem pior no desempenho profissional do que os diretores concursados ou especializados tecnicamente na função (SOUZA, 2008, p. 58).

Mas, se a formação inicial não parece ser diferenciadora, o que poderia ter impacto na qualidade do trabalho do diretor escolar em termos de formação continuada? Os conteúdos a serem abordados são importantes, mas precisam ser vinculados a elementos que tenham relação direta com a essência da função a ser desempenhada. Se as qualidades elogiáveis e, mais que isso, necessárias em um profissional docente que tem uma tarefa político-pedagógica são a disposição ao diálogo e à democracia e a capacidade de liderança (SOUZA, 2009), logo uma formação com enfoque gerencial e administrativo são secundadas por uma formação focada em questões relacionadas à política educacional, aos princípios do direito à educação e à educação democrática.

Nesse sentido, o material com o qual a Escola de Gestores tem trabalhado contribui na edificação de um perfil de dirigente escolar articulado com uma perspectiva de gestão democrática, que toma como condição para ser diretor, antes de tudo, ser um trabalhador docente, um educador. Pois, o material do curso pressupõe que a formação inicial de todo diretor tenha dado conta de apresentar-lhe importantes elementos pedagógicos do processo de ensinar e aprender, do processo educativo. A formação específica predominante para atuar na direção escolar, assim, não é uma formação técnico-administrativa, mas uma 
formação político-pedagógica, que complementa, aprofunda conhecimentos sobre os fundamentos do direito à educação, sobre as políticas educacionais e sua gestão, sobre a organização escolar e educacional no país, sobre o planejamento escolar e educacional, elementos que determinam os conteúdos das salas ambiente/disciplinas do referido curso.

Um aspecto muito importante na identidade e reconhecimento profissional, mesmo supondo que não se trate de um cargo, é a remuneração. No caso do dirigente escolar há ainda uma peculiaridade. Como essa função foi constituída, historicamente, para o cumprimento de uma responsabilidade de chefia de uma repartição pública (a escola), coube-lhe desde há muito tempo o pagamento de uma gratificação pela função que desempenha. Tal gratificação está articulada com possíveis responsabilidades inerentes à função e, por certo, pela tradição burocrática de verticalização das responsabilidades/poder com recompensa salarial proporcional. Ou seja, quanto mais "superior" está um trabalhador na escala burocrática de divisão do trabalho, maior sua remuneração.

Essa gratificação tem se reduzido proporcionalmente ao longo do tempo e não parece ter grande impacto no salário do diretor em âmbito nacional (SOUZA, 2007). De qualquer forma, ela é um estímulo à ocupação da função. Uma discussão que os sindicatos de trabalhadores da educação, bem como o poder público e a sociedade toda precisam fazer é se funções de comando/direção como essa devem ser mais bem remuneradas (na forma de gratificações) pelo simples fato de que o sujeito que ocupa a função tem responsabilidades de chefia. Trata-se de elemento complexo, uma vez que, em particular na educação escolar, os profissionais que estão sob maior pressão são os docentes, cuja responsabilidade é alta e progressivamente tem sido mais e mais cobrados.

Os dados mais adiante mostram como varia, entre o Brasil e o estado do Paraná, a diferenciação salarial entre diretores e professores. Mesmo que em âmbito nacional isso não seja mais tão significativo, ainda perdura essa discrepância.

A gratificação mencionada e a formação, também já apresentada, tem conexões com certo reconhecimento que se dá à função dirigente, como vimos. Nesse reconhecimento há leituras possíveis sobre as faces do trabalho docente desempenhado pelo diretor escolar. A (possível) contradição entre essas faces e a priorização de uma sobre as demais energiza os argumentos a favor de uma formação mais técnico-administrativa ou política ou pedagógica, ou, ainda, a (não) legitimidade do pagamento de uma gratificação para o desempenho da função. Senão vejamos.

De um lado, há a face técnico-administrativa da função. Inegavelmente, diretores têm por tarefa conduzir as escolas nos seus aspectos administrativos, como o acompanhamento de fluxo escolar discente, a gestão de pessoal (lotação, frequência, avaliação etc.), levantamentos e cobranças de recursos materiais junto aos canais competentes, dentre outros vários trabalhos. Assim, os cursos 
técnicos de preparação dos diretores são importantes e necessários porque lidam com a praticidade do campo. Além disso, há uma dimensão técnica presente na função do gestor escolar/educacional e que não é tratada em muitos cursos de formação continuada (SOUZA, 2008).

Mas, nessa face essencialmente é que os diretores são cobrados e se cobram pelo bom desempenho. Vale dizer que um bom diretor é tido como aquele que conduz adequadamente e com ótimos resultados as tarefas articuladas a essa face. É um equívoco tal leitura, pois, mesmo sendo importante, tal face é complementar à natureza da função dirigente e à função social da escola. Porém, dali deriva parte considerável das cobranças feitas por programas de formação para atuação no enfrentamento de problemas decorrentes dessa face.

Outra é a face política. Nela, todavia, diretores não se reconhecem como sujeitos políticos, ainda que operem nesse campo. Muitos daqueles que alcançam sucesso nessa face, tendem a fazer carreira na função ou em outros subcampos da política (institucional, partidário-eleitoral). Isso não é um problema em si, mas o retorno à função original do docente parece importante tanto para a rotatividade saudável no quadro dirigente, quanto para uma espécie de "devolução" dos conhecimentos adquiridos, quando na função dirigente, à função de origem. A liderança reclamada por essa face deriva, em alguma medida, da posição que exerce o diretor como representante do poder constituído, do Estado. De outro lado, ela também advém da posição de comando institucional que é própria à função do dirigente, dado que é responsável, como vimos, pela coordenação de um processo político que é a gestão escolar. A formação articulada a essa face tem conexão com aqueles elementos da gestão democrática e do desenvolvimento da liderança.

Por fim, a face pedagógica. Curiosamente, a despeito de ser reconhecida por (quase) todos como a mais importante face do trabalho do diretor escolar, os diretores alegam que não têm tempo ou condições para dar conta das tarefas desse campo. As tarefas de coordenação/direção pedagógicas são transferidas aos responsáveis técnicos, quando existem, como coordenadores pedagógicos (dentro da escola ou no sistema de ensino), ou mesmo aos docentes que precisam, nesse quadro, autogerir a pedagogia na escola. A formação para os diretores escolares que se articula a essa face trata propriamente de aspectos do processo educativo.

Parece-nos uma falsa questão procurar identificar em qual dessas faces se resume o trabalho do dirigente escolar. É inata à função todas essas faces e é seguro que em dados momentos faz-se necessário dedicar mais tempo e energia a aspectos relacionados a uma delas em especial.

Todavia, se a formação inicial do trabalhador docente contempla os aspectos predominantes da face pedagógica, a formação continuada pela qual passará o diretor escolar precisa aprofundar esses conhecimentos. 
De outro lado, se os docentes não têm formação inicial que trate de elementos técnico-administrativos, a formação continuada pode, aos diretores, franquear o acesso a esses conhecimentos, ainda que compreendamos que eles não são mais que complementares a um bom projeto de formação continuada.

Assim, reforçando os argumentos apresentados anteriormente, parece-nos que efetivamente o maior esforço na formação continuada do diretor escolar deve estar focalizado nos aspectos da política educacional e escolar. A condução da gestão escolar não pode dispor da ampliação dos conhecimentos pelos dirigentes e como essa formação amplia a base de conhecimentos e fortifica a experiência, a progressão na carreira docente parece quase natural. Isto quer dizer que estamos advogando que a remuneração do diretor escolar se articule com a sua experiência docente e com a sua formação, como de resto é o mesmo que se tem advogado para o crescimento na carreira para os demais trabalhadores docentes. A diferenciação salarial entre diretores e professores, dessa maneira, parece-nos equivocada.

O programa Escola de Gestores apresenta-se de alguma maneira na interface da discussão sobre esses dois elementos: formação e remuneração. No primeiro aspecto, por óbvio, o programa é uma proposta de formação continuada aos diretores de escolas públicas brasileiras. $\mathrm{O}$ enfoque do material do curso, realizado na modalidade a distância, recai nas questões do direito à educação, da política educacional e do planejamento escolar. Tal ênfase é importante porque demonstra uma concepção de gestão e gestor escolar que precisa mesmo ser destacada. Todavia, a ausência de discussões sobre aspectos técnico-administrativos inerentes à função precisa ser enfrentada. De maneira equivalente, o material também não prioriza a face pedagógica da função, ainda que a discussão sobre projeto político-pedagógico, em especial, busque, de alguma maneira, reforçar a essência pedagógica da função social da escola.

No que se refere ao outro elemento, a Escola de Gestores não trata nem no seu material, nem está evidente em qualquer dos seus documentos qualquer relação com salário ou remuneração de diretores escolares. Todavia, o programa tem sido ofertado na forma de curso de pós-graduação, nível de especialização. Em várias redes de ensino, país afora, a conclusão desse nível de formação permite/potencializa progressões na carreira docente. Assim, a formação ofertada pela Escola de Gestores pode contribuir tanto para a ampliação de conhecimentos pelos diretores escolares quanto para auxiliar no crescimento de suas carreiras docentes.

Essas análises podem ser complementadas pelos dados discutidos na sequência, sobre as pessoas que têm ocupado a direção escolar nas escolas públicas. 


\section{O que dizem as bases de dados sobre os diretores das escolas públicas ${ }^{4}$}

A tabela 1 permite uma apresentação inicial de quem são os diretores das escolas públicas básicas brasileiras e quem foram os alunos de 2008-2009 na UFPR no curso de especialização em Gestão Escolar - EAD. Observe-se que na amostra nacional os diretores de redes estaduais compõem 33\% dos respondentes, enquanto os diretores das redes municipais compõem outros $30 \%$. No caso dos alunos da Escola de Gestores/UFPR os oriundos da rede estadual do Paraná são $55 \%$ dos cursistas e aqueles oriundos das redes municipais são $45 \%$. Os cursistas do programa eram, no início do curso, advindos $50 \%$ de cada uma das duas redes de ensino, todavia, vimos uma maior evasão dos cursistas das redes municipais. A principal razão encontrada para explicar esta situação tem relação com o fato de que os diretores de escolas municipais enfrentaram, ao longo do curso, uma eleição municipal (para prefeito e vereadores) em suas cidades, e como muitos deles são indicados para o cargo de diretores, pode ter ocorrido que os resultados eleitorais locais tenham afastado alguns dos cursistas. Ainda que o programa garantisse a vaga para o cursista, mesmo ele/ela deixando de responder pela direção escolar ao longo do programa, é possível que situações políticas como aquela mencionada tenham algum impacto nas taxas de evasão ${ }^{5}$.

Com relação ao gênero, a maioria dos diretores da amostra do SAEB são mulheres, na turma 2008/2009. Entretanto, ainda que a maioria seja de diretoras, no caso da rede estadual, participaram, proporcionalmente, mais homens no curso do que mulheres. No grupo municipal, proporcionalmente, houve uma presença maior de mulheres. Isto encontra relação com o perfil que a literatura vem traçando sobre os dirigentes escolares (SOUZA, 2007; GOMES, 2004), no qual se evidencia que a presença de homens diretores de escolas das séries iniciais do ensino fundamental (dominantemente municipais) é proporcionalmente maior em escolas do norte e nordeste do país do que nas regiões mais ao sul. De qualquer sorte, a presença masculina na função dirigente escolar nas escolas do

4 As fontes de dados para esta análise são: a) questionários aplicados aos cursistas ao final das disciplinas/salas ambiente durante o curso de especialização em gestão escolar mencionado. Nem todos concluíram o curso, e o número de respondentes do questionário equivale a 50,3\% do total de diretores que iniciou o curso; b) questionário respondido pelos diretores das escolas públicas avaliadas no Sistema de Avaliação da Educação Básica (SAEB) de 2007.

5 A despeito de termos contato com 186 respondentes ao questionário na Escola de Gestores-PR, apenas 99 cursistas concluíram o curso com a entrega do Trabalho de Conclusão de Curso, em março de 2010, com direito ao certificado de especialista em Gestão Escolar. Parte dos cursistas, ao concluírem as disciplinas, tem direito a um certificado de aperfeiçoamento. 
ensino fundamental e do ensino médio vem se adequando ao número de professores homens, sugerindo uma redução de um possível quadro de discriminação de gênero no acesso às posições de poder na educação escolar (SOUZA, 2009).

TABELA 1 - NÚMERO DE DIRETORES RESPONDENTES DOS QUESTIONÁRIOS

\begin{tabular}{|c|c|c|c|c|c|c|c|}
\hline & & & \multicolumn{4}{|c|}{ Dependência administrativa } & \multirow{2}{*}{ Total } \\
\hline & & & Estadual & Federal & Municipal & Particular & \\
\hline \multirow{6}{*}{$\begin{array}{l}\text { SAEB } \\
2007\end{array}$} & & $\mathrm{n}$ & 526 & 20 & 355 & 504 & 1405 \\
\hline & Masculino & $\%$ & 26,2 & 62,5 & 19,6 & 23,1 & 23,3 \\
\hline & & $\mathrm{n}$ & 1478 & 12 & 1459 & 1677 & 4626 \\
\hline & Feminino & $\%$ & 73,8 & 37,5 & 80,4 & 76,9 & 76,7 \\
\hline & & $\mathrm{n}$ & 2004 & 32 & 1814 & 2181 & 6031 \\
\hline & Total & $\%$ & 100,0 & 100,0 & 100,0 & 100,0 & 100,0 \\
\hline \multirow{6}{*}{$\begin{array}{l}\text { Escola de } \\
\text { gestores }\end{array}$} & & $\mathrm{n}$ & 61 & 0 & 10 & 0 & 71 \\
\hline & Masculino & $\%$ & 32,8 & 0,0 & 6,7 & 0,0 & 21,1 \\
\hline & & $\mathrm{n}$ & 125 & 0 & 140 & 0 & 265 \\
\hline & Feminino & $\%$ & 67,2 & 0,0 & 93,3 & 0,0 & 78,9 \\
\hline & & $\mathrm{n}$ & 186 & 0 & 150 & 0 & 336 \\
\hline & Total & $\%$ & 100,0 & 0,0 & 100,0 & 0,0 & 100,0 \\
\hline
\end{tabular}

Fonte: MEC-INEP, Microdados SAEB 2007; Banco de dados dos pesquisadores.

Para avaliar os impactos de um curso de especialização, certamente a formação inicial é uma variável importante. E, quanto a este aspecto, os dados do SAEB 2007 evidenciam que a maior parte dos gestores das escolas de ensino fundamental e médio tem formação superior. Ainda que a ausência de ensino médio e a formação apenas em ensino médio sem a habilitação do curso normal, em $1 \%$ da amostra, sejam preocupantes, o quadro geral é positivo.

No caso da amostra da Escola de Gestores, por tratar-se de uma especialização, todos têm ensino superior. É curioso observar que, nos dados da tabela 2 , encontramos um percentual muito grande de professores habilitados em licenciaturas em geral que atuam na rede estadual do Paraná (79\%) e um número expressivo de pedagogos e professores com formação no Normal Superior provenientes das redes municipais (71\%). Isto tem uma explicação evidente: as redes municipais no Paraná atendem preferencialmente as séries iniciais do ensino fundamental, fase em que a formação exigida dos professores é Pedagogia e/ou Normal Superior. O contrário ocorre na rede estadual que atende os anos finais do ensino fundamental e o ensino médio. 
Esta distribuição não segue a mesma tendência da distribuição nacional, pois nos dados do SAEB o número de pedagogos é bastante mais próximo dos licenciados, nas duas dependências administrativas. A presença da formação em Normal Superior nacional também é consideravelmente menor que no caso paranaense. Isto pode sugerir que o conteúdo do curso tem algum aspecto mais interessante ao licenciado em geral do que aos pedagogos que, via de regra, têm disciplinas sobre gestão escolar na formação inicial.

Outro aspecto relevante é considerar que a Escola de Gestores tem atingido diretores que não tiveram outras formas de acesso à especialização. Ao tratar-se de uma modalidade a distância, vale considerar algumas possibilidades de variáveis de interesse dos cursistas: a ausência de outras oportunidades de formação e/ou o interesse na temática do curso, e evidentemente a combinação das duas - ausência de oportunidade de formação presencial nesta temática.

Os dados do SAEB 2007 informam que 63,5\% dos diretores de escola no Brasil já têm alguma especialização. Entre os cursistas da Escola de Gestores, um percentual alto (45\%) já possuía esta formação. Curioso é que no caso da rede estadual, $63 \%$ dos cursistas possuíam especialização, contra apenas $25 \%$ dos cursistas das redes municipais. Nota-se ainda que na rede estadual há um percentual, ainda que pequeno, de professores com mestrado entre os cursistas (1\%). O mesmo não acontece na dependência municipal. Esta questão tem implicações muito fortes sobre a necessidade de um programa como este, financiado pelo MEC, no contexto do regime de colaboração. Gomes, ao analisar a experiência da Escola de Gestores em Pernambuco, argumenta que "professores e dirigentes escolares de escolas localizadas em municípios distantes da capital sofrem com a ausência de políticas de formação de gestores escolares" (GOMES et al., 2009, p. 274), sendo que algo nesta mesma direção pode estar presente na experiência do Paraná. Todavia, como a rede estadual paranaense tem, há muitos anos, um mecanismo de progressão automática na carreira para aqueles profissionais que concluam curso de pós-graduação/especialização, a maioria dos cursistas do programa já possuíam tal título. É possível que a participação no programa esteja, para esses diretores, mais vinculada portanto ao conjunto de conhecimentos abordados pelo curso do que pela necessidade do título ou pela ausência de outras alternativas de formação. Assim, essa informação de que uma parte considerável dos cursistas na Escola de Gestores já possuía formação, especialmente na rede estadual, parece insinuar que o conteúdo do curso seria um atrativo para a procura. Isso é interessante à medida que a incorporação pelos planos de carreira do magistério do princípio do pagamento pela maior formação (necessário e louvável) criou, infelizmente, um mercado de especializações. Assim, a procura por um segundo curso pode ser indicador da busca de diretores por conteúdos específicos para melhorar seu trabalho. 
TABELA 2 - FORMAÇÃO INICIAL DOS DIRETORES DAS ESCOLAS PÚBLICAS

\begin{tabular}{cl|c|c|c}
\hline \multirow{2}{*}{} & & \multicolumn{2}{|c|}{$\begin{array}{c}\text { Dependência } \\
\text { administrativa }\end{array}$} & \multirow{2}{*}{ Total } \\
\cline { 3 - 4 } & Menos que o ensino médio & Estadual & Municipal & \\
\hline Ensino médio - Magistério & 0,1 & 0,1 & 0,1 \\
& Ensino médio - Outros & 3,4 & 5,9 & 4,6 \\
& Pedagogia & 0,8 & 1,1 & 0,9 \\
& Licenciatura & 31,4 & 41,9 & 36,4 \\
& Normal superior & 43,0 & 32,1 & 37,8 \\
SAEB & Superior - Outros & 2,0 & 3,4 & 2,7 \\
& Total & 19,3 & 15,5 & 17,5 \\
& Menos que o ensino médio & 100 & 100 & 100 \\
& Ensino médio - Magistério & 0,0 & 0,0 & 0,0 \\
& Ensino médio - Outros & 0,0 & 0,0 & 0,0 \\
& Pedagogia & 0,0 & 0,0 & 0,0 \\
& Licenciatura & 9,2 & 39,6 & 22,9 \\
& Normal superior & 79,4 & 22,1 & 53,6 \\
Escola de & Superior - Outros & 6,7 & 32,3 & 18,2 \\
gestores & Total & 4,7 & 6,0 & 5,3 \\
\hline
\end{tabular}

Fonte: MEC-INEP, Microdados SAEB 2007; Banco de dados dos pesquisadores.

TABELA 3 - FORMAÇÃO EM NÍVEL DE PÓS-GRADUAÇÃO DOS DIRETORES DAS ESCOLAS PÚBLICAS

\begin{tabular}{cl|c|c|c}
\hline \multirow{2}{*}{} & & \multicolumn{2}{|c|}{$\begin{array}{c}\text { Dependência } \\
\text { administrativa }\end{array}$} & \multirow{2}{*}{ Total } \\
\cline { 3 - 4 } & Atualização & Estadual & Municipal & \\
\hline \multirow{2}{*}{ Especialização } & 5,3 & 3,8 & 4,6 \\
& Mestrado & $\mathbf{6 6 , 4}$ & $\mathbf{6 0 , 3}$ & $\mathbf{6 3 , 5}$ \\
& Doutorado & 2,2 & 1,5 & 1,8 \\
SAEB & Não fiz ou não completei PG & 0,3 & 0,3 & 0,3 \\
& Total & 25,8 & 34,1 & 29,8 \\
& Atualização & 100 & 100 & 100 \\
& Especialização & 0,0 & 0,0 & 0,0 \\
& Mestrado & $\mathbf{6 3 , 0}$ & $\mathbf{2 5 , 0}$ & $\mathbf{4 5 , 9}$ \\
& Doutorado & 1,0 & 0,0 & 0,6 \\
Escola de & Não fiz ou não completei PG & 0,0 & 0,0 & 0,0 \\
gestores & Total & 36,0 & 75,0 & 53,6 \\
\hline
\end{tabular}

Fonte: MEC-INEP, Microdados SAEB 2007; Banco de dados dos pesquisadores.

Ainda que a especialização, na maioria dos casos, possa não estar relacionada a avanços funcionais, cabe considerar qual é a condição de remuneração dos diretores. Os dados do SAEB 2007 informam que a participação da remuneração de diretores na renda familiar é bastante significativa (81\%), e isto se 
reproduz no caso dos cursistas da Escola de Gestores, porém a razão é de 70\%, o que ainda que seja alto, não é igual.

A remuneração média de diretores no Brasil em 2007 era de $\mathrm{R} \$ 1.873$, enquanto a remuneração média de professores, segundo dados do SAEB, era de R 1.486 (SOUZA; GOUVEIA, 2010). Isto significa uma diferença de 20\% na média salarial.

Se considerarmos as condições no Paraná, a média salarial dos cursistas é $10 \%$ maior que a média nacional. Comparativamente aos rendimentos médios dos professores do estado, segundo dados de remuneração da Relação Anual de Informações Sociais (M.T.E, 2007), que informavam uma média de R 1.223 de remuneração entre professores da educação básica considerando dependência administrativa municipal e estadual, os salários dos cursistas na Escola de Gestores é, em média, $40 \%$ maior ${ }^{6}$. Pode-se contestar o fato de que são valores nominais. Entretanto, usaram-se valores nominais nas duas formas. Assim, parece haver um incremento maior das remunerações dos dirigentes escolares no Paraná em relação à média nacional, ainda que haja uma tendência geral de diferenciação.

TABELA 4 - REMUNERAÇÃO E RENDA FAMILIAR DOS DIRETORES DAS ESCOLAS PÚBLICAS

\begin{tabular}{l|c|c|c}
\hline & $\begin{array}{c}\text { Remuneração Média } \\
\text { Diretor }\end{array}$ & Renda Familiar Média & $\begin{array}{c}\text { Participação Remune- } \\
\text { ração/Renda }\end{array}$ \\
\hline SAEB 2007 & $\mathrm{R} \$ 1.873,08$ & $\mathrm{R} \$ 2.309,05$ & $81 \%$ \\
Escola de Gestores & $\mathrm{R} \$ 2.086,89$ & $\mathrm{R} \$ 2.974,93$ & $70 \%$ \\
\hline
\end{tabular}

Fonte: MEC-INEP, Microdados SAEB 2007; Banco de dados dos pesquisadores.

Os dois histogramas a seguir permitem identificar a tendência de distribuição dessas médias de remuneração. No caso nacional (gráfico 1), a dispersão é maior, com boa parte das remunerações concentradas entre quase mil reais e dois mil reais. No caso dos cursistas da Escola de Gestores (gráfico 2), a dispersão é bem menor. Ainda que existam salários muito pequenos e muito elevados nas pontas de fora da curva, o desvio padrão é comparativamente menor que o desvio na situação anterior. Assim, parece possível afirmar que os cursistas têm uma remuneração um pouco maior e mais equitativa no Paraná que a média nacional.

6 Uma explicação possível para esta diferença pode estar no Plano de Carreira do Magistério estadual que prevê um adicional de 50\% para os diretores considerando o nível e classe na carreira em que o sujeito está (PARANÁ, Lei Complementar 103/2004). Com mais tempo de serviço e melhor qualificação (variáveis previstas no incremento das remunerações), cresce a base sobre a qual o percentual incide. 


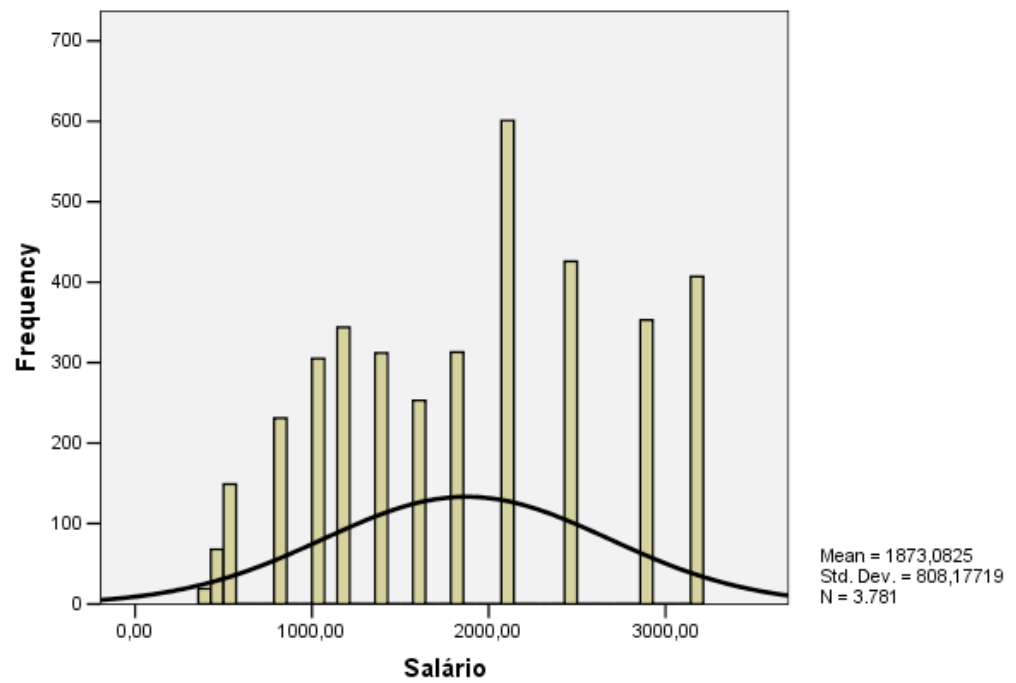

GRÁFICO 1 - HISTOGRAMA DO SALÁRIO DOS DIRETORES DAS ESCOLAS PÚBLICAS - SAEB 2007

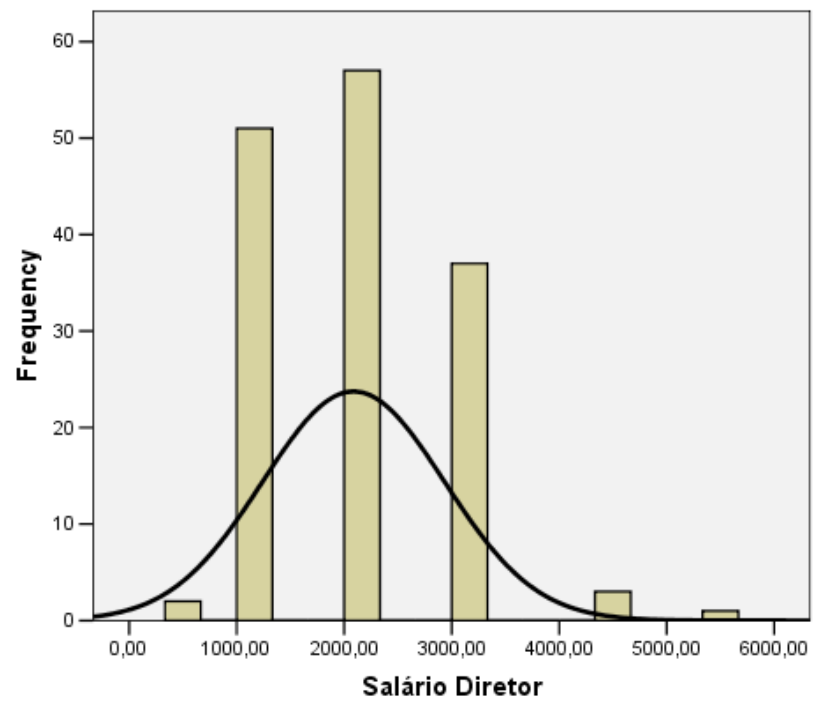

Mean $=2086,894$

Std. Dev. $=845,52631$ $\mathrm{N}=151$

GRÁFICO 2 - HISTOGRAMA DO SALÁRIO DOS DIRETORES DAS ESCOLAS PÚBLICAS - ESCOLA DE GESTORES/PR 
Uma das explicações para as condições salariais é a carreira docente. Esta é a condição de vínculo dos diretores, já que no caso paranaense não há carreira de diretores. Assim, observemos as condições de tempo de serviço e experiência dos diretores no Brasil e na turma 2008-2009 da Escola de Gestores.

Entre os diretores brasileiros observa-se que cerca de $70 \%$ tem mais de 16 anos de experiência. No caso dos cursistas da Escola de Gestores esta situação se repete, $66,2 \%$ tem mais de 16 anos de experiência, ainda que, neste caso, seja possível observar que perto da metade destes $(31,1 \%)$ tem entre 16 e 20 anos e a outra metade está no final da carreira, com mais de 20 anos. Quando se considera o tempo de direção escolar, os cursistas se aproximam muito do panorama nacional, sendo que a maior concentração está numa experiência de direção escolar de 3 a 5 anos de trabalho; mas há um número expressivo que tem entre 1 e 2 anos de experiência, no Brasil e entre os cursistas; e um número expressivo que tem entre 6 e 9 anos, nos dois grupos. Os dados da tabela 5 parecem indicar que a procura pelo curso da Escola de Gestores não tem relação com a falta de experiência, e, portanto, há uma necessidade de formação para enfrentar um novo desafio. Parece que a distribuição no curso apenas reproduz o cenário nacional de composição de tempo de serviço dos diretores.

Isso pode ser interpretado de diversas maneiras, mas especialmente duas devem ser consideradas: a concepção de gestão tem uma relação direta com o projeto político, com a conjuntura governamental. Assim, diretores estão sempre em busca de compreender qual é a concepção de gestão do momento; por outra via, o desafio colocado na Constituição Federal de construir-se uma gestão democrática na escola ainda requer debate e diretores, sejam experientes ou não, têm buscado este debate.

TABELA 5 - TEMPO NA EDUCAÇÃO E EM FUNÇÕES DE DIREÇÃO DOS DIRETORES DAS ESCOLAS PÚBLICAS

\begin{tabular}{|c|c|c|c|c|}
\hline & \multicolumn{2}{|c|}{ SAEB 2007} & \multicolumn{2}{|c|}{ Escola de Gestores } \\
\hline & $\begin{array}{l}\text { Tempo na Edu- } \\
\text { cação }\end{array}$ & $\begin{array}{l}\text { Tempo em Dire- } \\
\text { ção Escolar }\end{array}$ & $\begin{array}{l}\text { Tempo na Edu- } \\
\text { cação }\end{array}$ & $\begin{array}{l}\text { Tempo em Dire- } \\
\text { ção Escolar }\end{array}$ \\
\hline Menos de 1 ano & & & 0,7 & 9,3 \\
\hline De 1 a 2 anos & 0,4 & 25,9 & 0,7 & 18,7 \\
\hline De 3 a 5 anos & 1,2 & 31,3 & 3,3 & 36,0 \\
\hline De 6 a 9 anos & 12,4 & 26,8 & 6,0 & 18,0 \\
\hline De 10 a 15 anos & 16,4 & 8,7 & 23,2 & 10,0 \\
\hline De 16 a 20 anos & & & 31,1 & 5,3 \\
\hline Mais de 20 anos & 69,5 & 7,2 & 35,1 & 2,7 \\
\hline Total & 100,0 & 100,0 & 100,0 & 100,0 \\
\hline
\end{tabular}

Fonte: MEC-INEP, Microdados SAEB 2007; Banco de dados dos pesquisadores. 
Se considerarmos especialmente esta segunda interpretação, seria esperado que os diretores que buscaram a especialização no âmbito da Escola de Gestores ocupassem o cargo como decorrência de processos de escolha democráticos. Vejamos qual é o cenário nesta variável. Entre os diretores brasileiros, 27\% informaram, no SAEB 2007, terem sido escolhidos apenas por eleição. No caso da Escola de Gestores este número chega a 66\%.

Considerando o conteúdo do curso da Escola de Gestores, que, segundo a análise de Gomes, "procura consolidar a formação discursiva da gestão democrática da escola, assentada fortemente na educação como direito e na qualidade social da educação" (GOMES et al., 2009, p. 279), pode-se inferir que o programa tenha uma aderência interessante a este público de sujeitos eleitos para a função, por outro lado, pensando a garantia de condições para que as escolas construam-se de forma democrática, independente de processos eleitorais para escolha de diretores, é interessante que, inclusive, aqueles que tenham sido indicados para a função, possam discutir o que é o trabalho coletivo na escola.

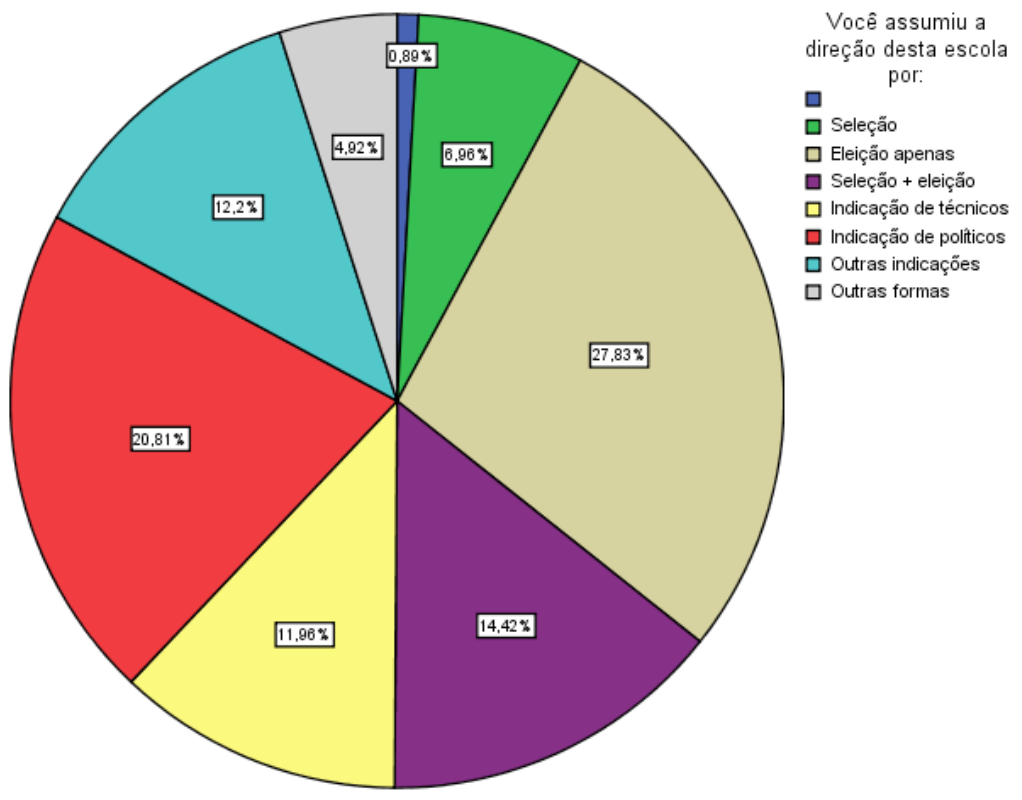

GRÁFICO 3 - FORMA DE PROVIMENTO DA FUNÇÃO DE DIRETOR - SAEB 2007 - ESCOLAS PÚBLICAS 


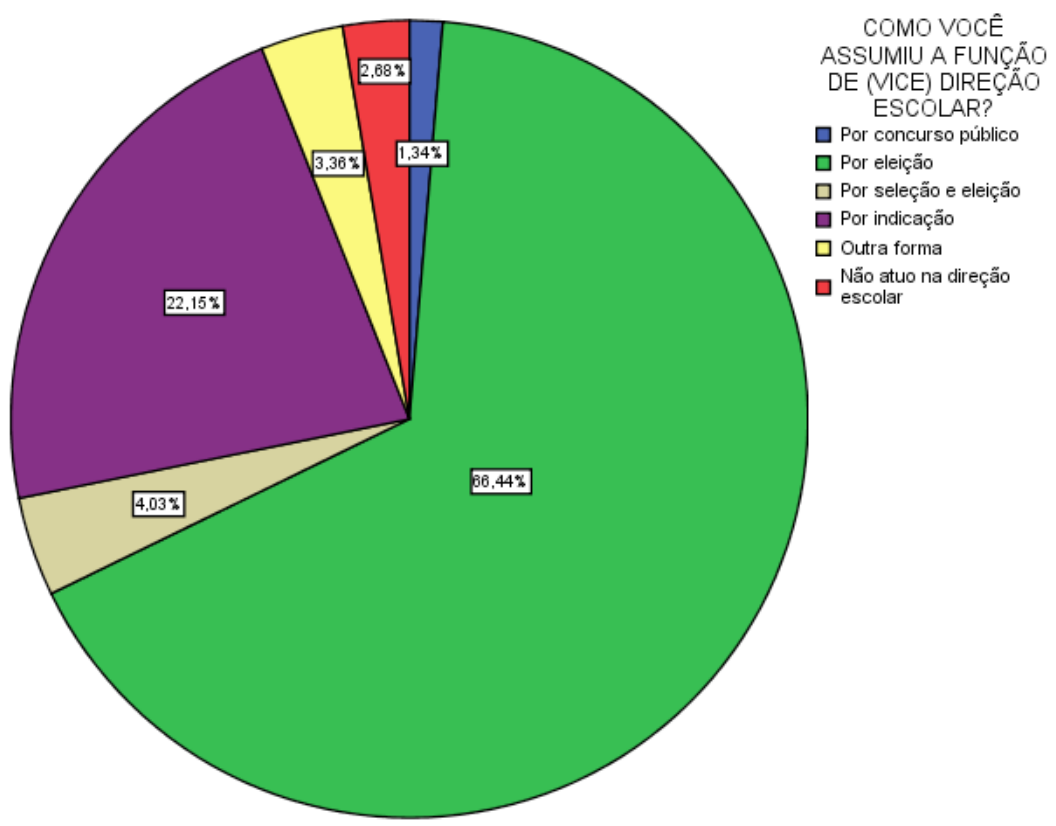

GRÁFICO 4 - FORMA DE PROVIMENTO DA FUNÇÃO DE DIRETOR - ESCOLA DE GESTORES/PR

\section{Notas finais: problemas e desafios para o trabalho e para o traba- lhador da direção escolar}

Vimos nesse artigo que a função do diretor escolar é composta por diferentes faces do trabalho docente. Concernente às faces técnico-administrativa, política e pedagógica, requer-se uma ampliação na noção de formação continuada para esses sujeitos que ocupam a função dirigente nas escolas. Mesmo afirmando que a direção escolar é uma função na qual predomina o domínio de política educacional e escolar, não é dispensável uma formação técnico-administrativa e, especialmente, de atualização de conhecimentos e procedimentos pedagógicos, dada a centralidade pedagógica na natureza da instituição escolar. 
O programa Escola de Gestores tem contribuído para a ampliação do conhecimento dos gestores escolares, mas tem focalizado suas atenções na face política, como vimos, e, em menor medida, na face pedagógica. Isso não é de pouca relevância, pois representa, em alguma medida, um câmbio importante na concepção de formação continuada de diretores, pois durante boa parte dos anos 1990 e início dos 2000, pareciam predominar formações com perspectivas bastante distintas dessa. Os resultados desse projeto precisam, ainda, ser cotejados com resultados educacionais e com a (possível) ampliação dos conhecimentos dos dirigentes escolares, de sorte a se avaliar com mais precisão a efetividade do programa Escola de Gestores.

Por fim, parece-nos importante que o trabalhador docente que assume a função de diretor de escola pública no Brasil precisa ser mais bem informado sobre a expectativa que se tem sobre o desempenho dessa função. Para tanto, também é necessário que a sociedade (em especial, os sindicatos de trabalhadores docentes, as administrações públicas e as universidades) discuta melhor o que é a natureza desse trabalho, pois isso tem consequências na noção de carreira, remuneração, formação inicial e continuada dos diretores escolares e formas de provimento.

\section{REFERÊNCIAS}

COLLARD, J. L. Leadership and Gender: an Australian perspective. Educational Management \& Administration, Londres: SAGE Publ., v. 29, n. 3, p. 343-355, 2001.

CORREA, V. S. Gestão escolar e gênero: o fenômeno do teto de vidro na educação brasileira. Dissertação (Mestrado em Educação) - Universidade Federal do Paraná, Curitiba, 2010.

ECKMAN, E. W. Similarities and differences in role conflict, role commitment, and job satisfaction for female and male High School principal. Educational Administration Quarterly, v. 40, n. 3, p. 366-387, Aug. 2004.

GATTI, B.; BARRETO, E. S. S. (Org.). Professores do Brasil: impasses e desafios. Brasília: UNESCO, 2009.

GOMES, A. M. et al. Escola de Gestores: política de formação em gestão escolar. Revista Brasileira de Política e Administração da Educação, Porto Alegre, v. 25, n. 2, p. 263-284, maio/ago. 2009. 
GOMES, F. C. O perfil dos diretores da Escola Fundamental e seus estilos de gestão. Um estudo a partir do Saeb 2001. Dissertação (Mestrado em Educação) - Pontifícia Universidade Católica do Rio de Janeiro, Rio de Janeiro, 2004.

LITTRELL, Janet; FOSTER, William. The myth of a knowledge base in educational administration. In: DONMOYER, R.; IMBER, M.; SCHEURICH, J.J. The knowledge base in educational administration: multiples perspectives. Albany/EUA: State University of New York, 1995.

MEC/INEP. Sinopse Censo Escolar 2007. Brasília. Disponível em: <http://www.inep. gov.br/basica/censo/default.asp>. Acesso em fev. 2009.

PARANÁ. Lei Complementar 103 de 2004. Institui Plano de Carreira do Professor da Educação Básica da Rede Estadual de Ensino. Disponível em: <http://www.inep.gov. br/basica/censo/default.asp $>$. Acesso em fev. 2009.

SOUZA, A. R. A produção do conhecimento e o ensino da gestão educacional no Brasil. Revista Brasileira de Política e Administração da Educação, v. 24, n. 1, p. 51-60, jan./abr. 2008.

SOUZA, A. R. Perfil da gestão da escola pública no Brasil: um estudo sobre os diretores escolares e sobre aspectos da gestão democrática. Revista Iberoamericana de Educación, v. 49, p. 1-17, 2009.

SOUZA, A. R. Perfil da Gestão Escolar no Brasil. Tese (Doutorado em Educação: História, Política, Sociedade) - Pontifícia Universidade Católica de São Paulo, São Paulo, 2007.

SOUZA, A. R.; GOUVEIA, A. B. Os trabalhadores docentes da educação básica no Brasil em uma leitura possível das políticas educacionais. In: ENCONTRO DE PESQUISA EM EDUCAÇÃO DA REGIÃO SUL, 8. Anais... Londrina: UEL, 2010.

Texto recebido em fevereiro de 2010

Texto aprovado em junho de 2010. 